\title{
STRATEGI KOMUNIKASI ORGANISASI PT TIGAMATA INDONESIA DALAM MENJALIN HUBUNGAN DENGAN PELANGGAN PERIODE MARET-JUNI 2013
}

\author{
Marta Sanjaya; Winki Octavianty \\ Marketing Communication Department, Faculty of Economic and Communication, BINUS University \\ Jln. K.H. Syahdan No. 9, Palmerah, Jakarta Barat 11480 \\ marta.sanjaya@gmail.com,winki.oct@gmail.com
}

\begin{abstract}
PT. Tigamata Indonesia is a company engaged in the service of graphic design or creative industries. PT Tigamata Indonesia is not a new company, because before using the name of PT Tigamata Indonesia, this company has become a business entity that already has quite a lot of customer. Thus, PT. Indonesian Tigamata need public relations to manage communications with customers. The purpose of this study was to determine the public relations strategy of PT. Tigamata Indonesia in the communication between the company and the customer. The method used is qualitative-descriptive. Data were analyzed by using a technique that consists of data collection, data reduction, data display and conclusion. The results showed PT. Tigamata Indonesia has done public relations strategy in the form of communication through various media to build relationships with customers. The conclusion of this study is PT. Tigamata Indonesia has not reached a clear public relations strategy because of the lack of knowledge of the field of public relations company. It takes a more structured system of communication so that communication can be managed better and achieve maximum results. Therefore, PT. Tigamata Indonesia needs the concept of Customer Relationship Management (CRM) to enhance public relations strategy that is already owned by the company.
\end{abstract}

Keywords: Strategy, organization communications, public relations, customers relationship management (CRM)

\begin{abstract}
ABSTRAK
PT. Tigamata Indonesia merupakan sebuah perusahaan yang bergerak dibidang jasa desain grafis atau industri kreatif. PT Tigamata Indonesia bukan perusahaan baru, karena sebelum menggunakan nama PT Tigamata Indonesia, perusahaan ini sudah menjadi badan usaha yang sudah memiliki pelanggan cukup banyak. Dengan demikian, PT. Tigamata Indonesia membutuhkan public relations untuk mengelola komunikasi dengan pelanggannya. Tujuan penelitian ini adalah untuk mengetahui strategi public relations PT. Tigamata Indonesia dalam melakukan komunikasi antara perusahaan dengan pelanggan. Metode yang digunakan adalah kualitatifdeskriptif. Data dianalisis dengan menggunakan teknik yang terdiri dari pengumpulan data, reduksi data, display data dan kesimpulan. Hasil penelitian menunjukkan PT. Tigamata Indonesia sudah melakukan strategi public relations berupa komunikasi melalui berbagai media untuk menjalin hubungan dengan pelanggannya. Kesimpulan dari penelitian ini adalah PT. Tigamata Indonesia belum mencapai strategi public relations secara jelas karena minimnya pengetahuan perusahaan terhadap bidang public relations. Dibutuhkan sebuah sistem komunikasi yang lebih terstruktur agar komunikasi tersebut dapat dikelola lebih baik dan mencapai hasil yang maksimal. Oleh karena itu, PT. Tigamata Indonesia membutuhkan konsep Customer Relationship Management (CRM) untuk menyempurnakan strategi public relations yang sudah dimiliki oleh perusahaan.
\end{abstract}

Kata kunci: Strategi,komunikasi organisasi, public relations, customers relationship management (CRM) 


\section{PENDAHULUAN}

PT. Tigamata Indonesia merupakan salah satu usaha bisnis di bidang pelayanan produk jasa yang bergerak pada design graphic agency. Perusahaan ini menyediakan berbagai variasi dari konsep kreatif, ide dan desain. Perusahaan ini memiliki fokus di bidang desain kemasan atau packaging, desain komunikasi perusahaan, desain publikasi, desain promosi, desain multimedia, desain web, fotografi dan merancang untuk memproduksi apakah itu merupakan pesanan dalam jumlah terbatas, sehingga untuk tujuan komersial, atau massa kuantitas pesanan, seperti yang terkait dengan tujuan promosi. Perusahaan ini memiliki tim profesional, seniman terampil dan desainer grafis kreatif, memberi jaminan terhadap pelayanan desain dan layanan pelanggan. Perusahaan ini juga menyediakan desain yang sangat kreatif, kuat dan unik yang mendukung bisnis suatu perusahaan. Saat ini keberadaan agency dalam bidang desain grafis sudah menjamur. Pesaing dari perusahaan ini tidak hanya perusahaan tetapi juga para freelancer di bidang desain grafis yang menawarkan jasa pelayanan yang serupa.

PT. Tigamata Indonesia dipilih pelanggan karena alasan fungsional sebagai agen desain grafis, tetapi juga hal lebih yang ditawarkan yaitu konsep ide kreatif yang lebih mendalam sehingga secara langsung atau tidak, dapat menguntungkan pihak pelanggan. Meskipun terbilang sebagai perusahaan baru dan belum terlalu besar, PT. Tigamata Indonesia sudah memiliki beberapa pelanggan dan yang menggunakan jasa dari perusahaan ini bukanlah pelanggan biasa, melainkan perusahaan-perusahaan besar. Di tengah arus persaingan PT. Tigamata Indonesia sebagai perusahaan baru yang sedang berkembang dituntut untuk tetap menjalin hubungan dengan para pelanggannya. Bagaimana PT. Tigamata Indonesia sebagai perusahaan penyedia produk jasa melakukan komunikasi kepada pelanggannya. Komunikasi yang dipakai oleh perusahaan pastilah merujuk pada strategi komunikasi organisasi yang dilakukan kepada pihak eksternal perusahaan yaitu kepada para pelanggannya.

Dalam menjalankan akitifitasnya PT. Tigamata Indonesia, belum memiliki divisi public relations karena perusahaan ini masih baru berdiri sehingga menurut perusahaan divisi ini masih belum terlalu penting untuk berdiri sendiri. Akan tetapi, peranan public relations di perusahaan ini tetap berjalan di bawah kendali promotion department. Hal tersebut tidak mengurangi bagaimana department tersebut bekerja dengan strategi public relations yang ada. Kegiatan public relation yang dilakukan oleh promotion department PT. Tigamata Indonesia adalah berkaitan dengan komunikasi organisasi. Department ini bertugas untuk melakukan komunikasi kepada pihak-pihak yang menjadi stakeholders dari perusahaan.

\section{METODE}

Penelitian ini menggunakan pendekatan kualitatif deskriptif. Peneliti menggunakan penelitian kualitatif deskriptif karena, peneliti ingin melihat fenomena-fenomena komunikasi yang terjadi pada PT. Tigamata Indonesia dalam membangun hubungan dengan para pelanggannya dan objek penelitian merupakan perusahaan yang interaksi jual belinya adalah business to business. Pelanggan dari perusahaan bukan masyarakat pada umumnya, melainkan perusahaan-perusahan besar. Selain karena hal tersebut, menggunakan metode penelitian kualitatif adalah agar dapat menjelaskan penelitian secara lebih mendalam.

Pada penelitian ini, yang menjadi sumber data adalah sumber data primer dan sumber data sekunder. Sumber data primer adalah hasil dari wawancara mendalam kepada para informan. Wawancara mendalam (intensive or depth interview) adalah teknik mengumpulkan data atau informasi dengan cara bertatap muka langsung dengan informan agar mendapatkan data yang mendalam 
(Ardianto, 2011). Dalam melakukan wawancara, pertanyaan yang sesuai dengan penelitian bebas ditanyakan dan informan atau responden yang menjawab bebas untuk memberikan jawaban yang lengkap dan mendalam atau bahkan tidak ada jawaban yang disembunyikan. Informan dalam wawancara ini adalah Direktur Utama dan head of promotion department PT. Tigamata Indonesia.

\section{HASIL DAN PEMBAHASAN}

Pengolahan data dari penelitian yang dilakukan adalah sebagai berikut:

Tabel 1 Komunikasi Organisasi

\begin{tabular}{ll}
\hline \multicolumn{1}{c}{ Komunikasi Organisasi } \\
1.Bapak Wahyudi & $\begin{array}{l}\text { Terkait dengan strategi komunikasi organisasi, strategi yang } \\
\text { dilakukan untuk menjalin hubungan dengan pelanggan adalah } \\
\text { dengan melalui pengiriman email, melalui temu tatap muka/rapat } \\
\text { dan juga memperbaharui informasi melalui jejaring media sosial. }\end{array}$ \\
& $\begin{array}{l}\text { Terkait dengan strategi dalam hal komunikasi organisasi, menurut } \\
\text { Bapak Chattra Mahottama selaku head of promotion department, } \\
\text { department ini melakukan hubungan komunikasi dengan } \\
\text { pelanggannya berupa pengajuan penawaran kerja sama. Melakukan } \\
\text { Mahottama }\end{array}$ \\
$\begin{array}{l}\text { promosi mengenai perusahaan, menginformasikan mengenai produk } \\
\text { yang dimiliki, penawaran harga yang diajukan oleh PT. Tigamata } \\
\text { Indonesia dan juga dimana posisi perusahaan sehingga dapat } \\
\text { menemui kantor apabila ingin menjalin kerjasama lebih lanjut. }\end{array}$
\end{tabular}

Tabel 2 Public Relations

\begin{tabular}{ll}
\hline \multicolumn{1}{c}{ Public Relations } \\
\hline Bapak Wahyudi & Pada PT. Tigamata Indonesia, peran public relations dilakukan oleh \\
Prasetyo & promotion department. Tidak semua peran public relations \\
& dijalankan oleh PT. Tigamata Indonesia. Menurut Bapak Wahyudi \\
& Prasetyo, peran public relations yang dilakukan adalah sebagai \\
& communicator dan juga sebagai bagian dari perusahaan yang \\
& bertugas untuk membina hubungan baik dengan pelanggan \\
& perusahaan. \\
& Menurut Bapak Chattra Mahottama, berkaitan dengan peran public \\
& relations di perusahaan, memanglah belum dilakukan secara \\
maksimal. Banyak kegiatan public relations yang belum dikerjakan. \\
Selain karena memang ada peran yang tidak Diperlukan oleh \\
perusahaan, tetapi juga memang karena minimnya pengetahuan \\
public relations yang dimiliki oleh pimpinan di PT. Tigamata \\
Indonesia. Meskipun demikian, masih menurut Bapak Chattra \\
Mahottama, ada beberapa kegiatan yang dilakukan oleh perusahaan \\
yang mendekati peran public relations. Diantaranya adalah, menjadi \\
saluran komunikasi antara Pihak PT. Tigamata Indonesia dengan \\
para pelanggannya. \\
Selain itu, PT. Tigamata Indonesia selalu memberikan informasi \\
perusahaan kepada pelanggannya. Selain itu melakukan publikasi \\
yaitu penyebaran inforasi melalui penempatan di media sosial dan \\
juga melakukan lobbying pada saat melakukan rapat dengan \\
pelanggan.
\end{tabular}


Tabel 3 Customers Relationship Management

\begin{tabular}{|c|c|}
\hline \multicolumn{2}{|r|}{ Hubungan Dengan Pelanggan } \\
\hline $\begin{array}{l}\text { Bapak Wahyudi } \\
\text { Prasetyo }\end{array}$ & $\begin{array}{l}\text { Menurut Bapak Wahyudi Prasetyo, perusahaannya senantiasa } \\
\text { melakukan organisasi dengan pelanggannya baik secara langsung } \\
\text { ataupun melalui media sosial. } \\
\text { PRT. Tigamata Indonesia belum mengetahui secara jelas dan rinci } \\
\text { mengenai konsep customer relationship management. Menurut } \\
\text { beliau, belum adanya sistem khusus yang ditujuukan untuk menjalin } \\
\text { hubungan dengan pelangggannya. Saat ini PT. Tigamata Indonesia } \\
\text { hanya menjalani hubungan komunikasi yang bersifat standar saja. }\end{array}$ \\
\hline $\begin{array}{l}\text { Bapak Chattra } \\
\text { Mahottama }\end{array}$ & $\begin{array}{l}\text { Menurut Bapak Chattra, memnga harus ada orang } \\
\text { yang ahli dengan dunia public relations sehingga dapat menambah } \\
\text { wawasan dan juga pengetahuan perusahaan mengenai bagaimana } \\
\text { cara menjalin dan mengelola hubungan dengan pelanggan. Selain } \\
\text { itu, perlu adanya perubahan sistem dan cara perusahaan dalam } \\
\text { menjalin hubungan dengan pelanggannya. }\end{array}$ \\
\hline
\end{tabular}

Berdasarkan pernyataan dari informan di atas, proses menjalin dan mengelola hubungan komunikasi dalam komunikasi pemasaran selama ini kegiatan berjalan dengan cukup lancar. Hambatan yang ada dirasakan memang cukup menjadi kendala bagi PT. Tigamata Indonesia. Minimnya pengetahuan mengenai dunia public relations mengakibatkan kegiatan hubungan komunikasi perusahaan dengan pelanggannya menjadi tidak maksimal. Berdasarkan hasil penelitian dalam penyajian dan pengolahan data, kesimpulan yang dapat diambil adalah PT. Tigamata Indonesia sudah melakukan kegiatan membangun dan mengelola hubungan dengan pelanggan. Sedikit banyak hal tersebut telah memberikan nilai positif bagi hubungan yang sudah dimiliki antara perusahaan dan pelanggan

Dalam menyampaikan Informasi PT. Tigamata Indonesia melalui media digital atau jejaring media sosial seperti facebook, twitter, channel youtube, dan website resmi serta kunjungan pelanggan ke kantor PT. Tigamata Indonesia ataupun sebaliknya. Namun ada beberapa kendala atau hambatan yang terdapat pada sistem yang berpengaruh pada perusahaan yaitu minimnya pengetahuan perusahaan terhadap kegiatan dan peran public relations secara menyeluruh. Berdasarkan hasil pengolahan data di atas, dapat dilakukan evaluasi yaitu keterbatasan pengetahuan mengenai dunia public relations membuat kinerja perusahaan kurang maksimal dalam membangun customer relationship management. Diperlukan suatu sistem dan juga cara yang lebih terstruktur agar dapat memaksimalkan kinerja yang sudah ada pada perusahaan.

Kegiatan komunikasi yang dilakukan oleh PT. Tigamata Indonesia menurut teori yaitu definisi komunikasi menurut Murphy dalam Nurjaman dan Umam (2012) menyatakan bahwa komunikasi adalah proses yang memungkinkan seseorang (komunikator) menyampaikan rangsangan (biasanya lambang-lambang verbal) untuk mengubah perilaku orang lain (komunikan). Hal ini dimaksudkan bahwa PT. Tigamata Indonesia sebagai pihak komunikator memberikan dan juga menyampaikan rangsangan untuk mempengaruhi perilaku pihak lain aitu pelanggannya yang dalam ini merupakan sebagai komunikan. Dalam penelitian yang dilakukan ini, jenis komunikasi PT. Tigamata Indonesia adalah komunikasi antar pribadi yang dilakukan baik komunikasi secara verbal maupun nonverbal. Komunikasi ini dilakukan karena antara pihak perusahaan PT. Tigamata Indonesia yang diwakili oleh promotion staff atau public relations dalam menjalin hubungan komunikasi dengan para pelanggan dari perusahaan melalui komunikasi langsung baik dengan surat maupun telepon.

Unsur-unsur komunikasi organisasi pada PT. Tigamata Indonesia berkaitan dengan fungsi komunikasi organisasi yaitu to tell, to sell dan juga dengan fungsi sebagai sarana relasi. Dengan cara 
ini, produk yang akan dipromosikan menyampaikan pesan dengan tepat pada target pelanggan. Salah satu komunikasi organisasi yang dilakukan adalah komunikasi eksternal yaitu direct marketing berupa pengiriman brosur dan booklet pada e-mail, serta menghubungi langsung via telepon. Mengenai segi public relations, meskipun tidak diisi khusus untuk menjalankan peran ini PT. Tigamata Indonesia melakukan kegiatan public relations sesuai dengan pengertian definisi public relations menurut Harlow (dalam Nova, 2011). Kegiatan yang dilakukan oleh promotion staff PT. Tigamata Indonesia dalam membangun hubungan dengan pelanggan yaitu membantu pembentukan dan pemeliharaan garis komunikasi dua arah, saling pengertian, penerimaan, dan kerjasama antara organisasi dan masyarakatnya yang melibatkan dalam manajemen problem atau masalah.

Dalam segi customer relationship management menurut Newell (dalam Widjaja, 2008), customer relationship management adalah proses memodifikasi prilaku konsumen dari waktu ke waktu dan belajar dari tiap interaksi, merubah, merawat pelanggan, dan memperkuat ikatan pelanggan dengan perusahan. Berdasarkan penjelasan mengenai definisi customer relationship management di atas adalah memang benar bahwa PT. Tigamata Indonesia perlu membangun customer relationship management, karena pada penelitian ini ditemukan bahwa minimnya pengetahuan perusahaan akan public relations membuat PT. Tigamata Indonesia tidak dapat menerapkan peran public relations secara baik dan tepat.

Sedangkan Menurut Hamidin (2008) aktivitas customer relationship management pada dasarnya bertujuan agar perusahaan dapat mengenali pelanggan secara lebih detil dan melayani sesuai dengan kebutuhan. Secara umum, beberapa aktivitas utama dari konsep customer relationship management adalah sebagai berikut: (1) Membangun database pelanggan yang kuat database pelanggan yang kuat merupakan kunci utama pelaksanaan CRM. Ada banyak alasan mengapa perusahaan perlu membangun database pelanggan yang kuat. Pertama, database pelanggan adalah salah satu aset utama perusahaan yang juga dapat dihitung performanya. Kedua, database pelanggan dapat dijadikan ukuran tentang "nilai perusahaan sekarang” dan kemungkinan performanya di masa mendatang. (2) Membuat profil dari setiap pelanggan langkah selanjutnya adalah membuat profil dari masing-masing pelanggan. Profil pelanggan menyangkut segala aktivitas yang dilakukan oleh pelanggan mengenai penggunaan produk ataupun layanan perusahaan. Profil pelanggan akan memberikan gambaran tentang kebutuhan, keinginan dan juga concern mereka tentang produk atau layanan perusahaan. Digabungkan dengan data-data demografis, psikografis dan berbagai data pendukung lain, profiling semacam ini akan memberikan gambaran yang lebih komprehensif tentang kebutuhan dan keinginan pelanggan. (3) Analisis profitabilitas dari tiap-tiap pelanggan. Dalam analisis profitabilitas, ada dua hal yang dinilai dari masing-masing pelanggan. Pertama adalah penerimaan (revenue) yang dihasilkan masing-masing pelanggan, dan kedua adalah biaya (cost) yang harus dikeluarkan untuk melayani masing-masing pelanggan. (4) Interaksi dengan pelanggan yang lebih targeted dan customized. Dengan profil yang lebih jelas, perusahaan akan lebih mudah untuk melihat kebutuhan yang berbeda-beda dari setiap pelanggan. Selain aktivitas komunikasi yang lebih targeted, perusahaan juga dapat memberikan penawaran produk ataupun layanan yang secara khusus di desain berbeda untuk setiap pelanggan. Dengan demikian, karena perusahaan sudah dapat mengenali kebutuhan pelanggan, tentunya akan lebih mudah bagi mereka untuk melakukan respon dan transaksi. Sehingga perusahaan dapat mendesain program loyalitas (loyality program) yang sesuai untuk pelanggannya. Program loyalitas ini akan sangat membantu perusahaan dalam mempertahankan pelanggan, meningkatkan kepuasan dan menjaga agar pelanggan agar tidak tergiur oleh berbagai tawaran yang diberikan oleh competitor lain.

Dalam penerapannya customer relationship management memiliki tujuan menurut Widjaja (2008) yaitu untuk menghasilkan ekuitas pelanggan yang tinggi. Ekuitas pelanggan adalah total nilai seumur hidup semua pelanggan perusahaan yang di-diskonto-kan. Semakin setia pelanggan, semakin tinggi pula ekuitas pelanggan. Sedangkan penjelasan mengenai tujuan Customer Relationship Management (CRM) adalah sebagai berikut: (1) Attraction (daya tarik) - Merupakan strategi yang dimiliki perusahaan untuk mengikat pelanggan yang memiliki kemampuan untuk dapat menjalin usaha 
dalam jangka panjang yang menguntungkan. Daya tarik yang dikeluarkan perusahaan merupakan kemampuan total dari seluruh resource (sumber daya) sehingga pelanggan akan merasakan keandalan dari perusahaan tersebut. (2) Retention (penjagaan) - Sikap perusahaan untuk menjalankan hubungan dengan pelanggan yang bernilai guna menciptakan pasar dan hubungan baik dalam jangka waktu yang panjang dengan memberikan pelayanan-pelayanan yang prima dan terus mengembangkan moto produk atau jasa dan layanannya. (3) Enchancement (peningkatan hubungan) - Yaitu partnership atau kemitraan yang dijalin untuk memperoleh posisi di pasar yang berkelanjutan. Hubungan yang dekat dengan pelanggan akan memberikan kenyamanan secara personal sehingga pelanggan akan merasa terintegrasi dengan perusahaan dan merasa memiliki dengan perusahaan.

Pada dasarnya customer relationship management bertujuan untuk mengelola proses adaptasi antara perusahaan dengan pelanggan. Program customer relationship management yang diterapkan dengan baik adalah seperti benang yang menjalar keseluruh perusahaan. Akhirnya tujuan customer relationship management adalah untuk berkomunikasi dan berinteraksi dengan satu pelanggan. Penjelasan mengenai tujuan dari customer relationship management sangat dapat terlihat bahwa sesuai dengan tujuan perusahaan. Penerapan customer relationship management yang benar pada PT. Tigamata Indonesia akan meningkatkan ekuitas pelanggan yang berbanding lurus dengan loyalitas pelanggan terhadap perusahaan, yang mana hal tersebut adalah dampak baik yang diharapkan oleh perusahaan.

\section{SIMPULAN}

Berdasarkan hasil analisis yang dilakukan peneliti dalam "Strategi Komunikasi Orgaanisasi PT. Tigamata Indonesia Dalam Menjalin Hubungan Dengan Pelanggan (Periode Maret-Juni 2013)”, maka dapat diperoleh simpulan sebagai berikut ini: (1) PT. Tigamata Indonesia merupakan sebuah perusahaan penyedia jasa desain grafis yang masih terbilang perusahaan baru. (2) Karena keberadaannya yang masih sebagai perusahaan baru, pengetahuan akan dunia public relations masih sangat minim. (3) PT. Tigamata Indonesia secara garis besar hanya berkomunikasi organisasi dengan menggunakan strategi public relations berupa publikasi dan lobbying. Sedangkan komunikasi yang dikhususkan untuk membangun dan mengelola hubungan dengan pelanggan belum ada. Hal ini menyebabkan pola komunikasi yang ada tidak dapat berjalan maksimal. (4) Minimnya pengetahuan tersebut menjadi kendala sehingga PT. Tigamata Indonesia tidak dapat meningkatkan hubungan yang sudah terbina dengan pelanggannya.

Beberapa hal layal untuk disarankan kepada beberapa pihak, seperti sebagai berikut: (1) Untuk peneliti: Dengan penelitian ini, ilmu public relations yang sudah didapatkan selama masa pendidikan dapat diterapkan dengan baik. (2) Untuk akademis: Diharapkan kepada mahasiswa dan mahasiswi yang ingin melakukan penelitian dan penulisan tugas akhir lebih memperhatikan lagi tema penelitian yang akan dipilih. (3) Untuk perusahaan: Agar perusahaan menerapkan sebuah sistem/konsep yang disebut Customer Relationship Management.

Mengadaptasi dari konsep menurut Hamidin (2008) aktivitas Customer Relationship Management bertujuan agar perusahaan dapat mengenali pelanggan secara lebih detail dan melayani sesuai dengan kebutuhan. Secara umum, beberapa aktivitas utama dari konsep Customer Relationship Management adalah sebagai berikut: (1) Membangun database pelanggan yang kuat yang merupakan kunci utama pelaksanaan Customer Relationship Management. Pada PT. Tigamata Indonesia, database pelanggan adalah salah satu aset utama perusahaan yang juga dapat dihitung performanya. Database pelanggan yang dimiliki oleh PT. Tigamata Indonesia dapat dijadikan ukuran tentang "nilai perusahaan sekarang” dan kemungkinan performanya di masa mendatang. (2) Membuat profil dari masing-masing pelanggan. Profil pelanggan yang dibuat oleh PT. Tigamata Indonesia harus 
menyangkut segala aktivitas yang dilakukan oleh pelanggan mengenai penggunaan produk ataupun layanan perusahaan. Profil pelanggan yang dibuat akan memberikan gambaran tentang kebutuhan, keinginan dan juga concern mereka tentang produk atau layanan perusahaan dari pelanggan. (3) Interaksi dengan pelanggan yang lebih targeted dan customized. Dengan profil yang dimiliki oleh PT. Tigamata Indonesia yang lebih jelas, perusahaan akan lebih mudah untuk melihat kebutuhan yang berbeda-beda dari setiap pelanggan. Selain aktivitas komunikasi yang lebih targeted, Perusahaan juga dapat memberikan penawaran produk ataupun layanan yang secara khusus didesain berbeda untuk setiap pelanggan. Dengan demikian karena PT. Tigamata Indonesia sudah dapat mengenali kebutuhan pelanggan, tentunya akan lebih mudah bagi mereka untuk melakukan respon dan transaksi.

\section{DAFTAR PUSTAKA}

Ardianto, E. (2011). Metode Penelitian Untuk Public Relations. Jakarta: Simbiosa Rekatama Media.

Hamidin, D. (2008). Model Customer Relationship Management (CRM) di institusi pendidikan. Jurnal Seminar Nasional Aplikasi Teknologi Informasi.

Nova, F. (2011). Crisis Public Relations. Jakarta: PT. RajaGrafindo Persada.

Nurjaman, K., Umam, K. (2012). Komunikasi dan Public Relations. Jakarta: CV. Pustaka Setia.

Tunggal, A. W. (2008). Dasar-dasar Customer Relationship Management (CRM). Jakarta: Harvarindo. 